\title{
Bangladeshis to sue over arsenic poisoning
}

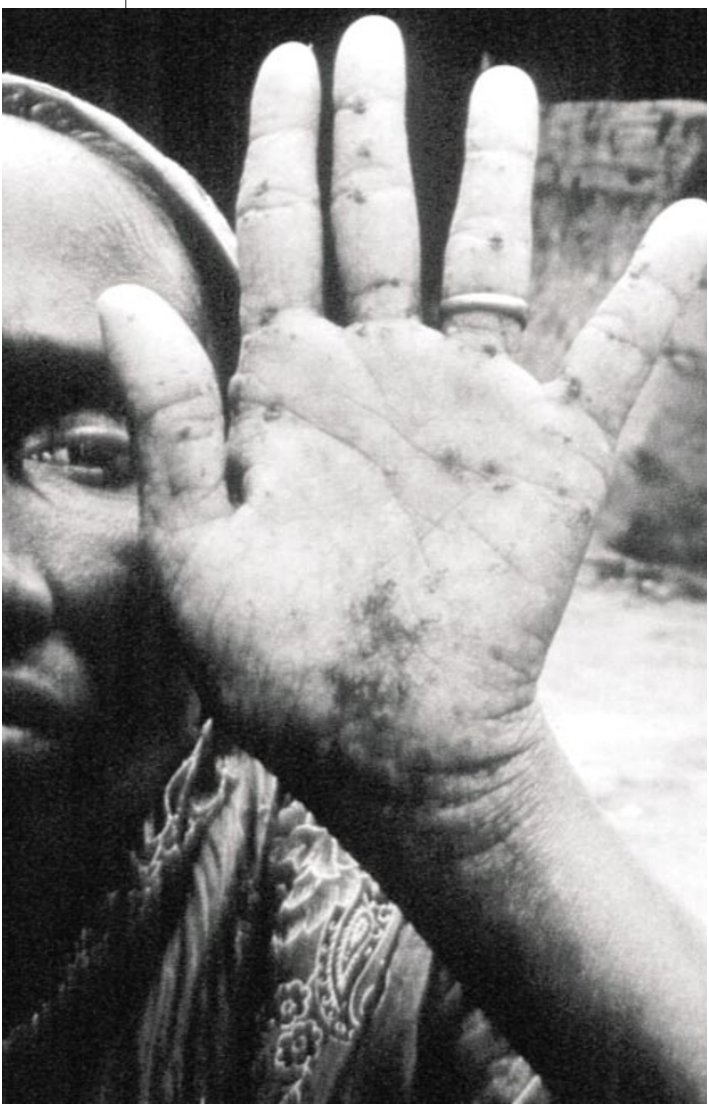

Telling signs: drinking contaminated water causes calluses on the palms, leading to cancers.
Tom Clarke, London

The British Geological Survey (BGS) is preparing to defend itself against a threatened lawsuit alleging that it is partly to blame for what has been described as the worst mass poisoning in history.

The claimants are Bangladeshi villagers who drank arsenic-contaminated water from wells dug by the BGS during the 1980s and early 1990s. The number of claimants could run into thousands. They intend to file a group-action suit in Britain alleging that the BGS's failure to test the well-water for arsenic makes the agency responsible for their poisoning.

On legal advice, BGS officials declined to be interviewed about the allegations. But in a statement, the BGS vigorously denies culpability: "Any legal claims, which we regard as wholly misconceived, will be resisted."

The suit is being prepared by Leigh, Day and Co., a London-based law firm that specializes in this type of case. Some researchers fear that the threat of such suits may deter scientists from working on aid projects in the developing world.

The claim against the BGS is expected to hang on the accusation that, when its scientists returned to Bangladesh in 1992 to assess the safety of the water in the wells they had dug, they did not test for arsenic.

The BGS statement argues that, at this time, arsenic was not a recognized contami-

\section{Spain's postdoc plan takes off}

Xavier Bosch, Barcelona

The Spanish science ministry has announced the first 800 appointments to its new Ramón y Cajal programme, a tenuretrack plan aimed at increasing competition for postdoctoral positions in the country's research institutions.

The Cajal programme, named after the Nobel-prizewinning neuroscientist, was launched earlier this year (see Nature 410, \& $1014 ; 2001)$. Successful applicants are offered five-year contracts, receive a salary of Ptas4.75 million (US\$26,300), which is similar to that of a university professor, and are able to run their own projects.

Of the new Cajal scholars, 169 will return home from positions abroad - something the programme was designed to encourage. Life sciences gains the most researchers, with 150 new appointments for genetics and molecular and cellular biology, followed by physical and space sciences with 80 and chemistry also with 80 . But the ministry has complained of a lack of high-quality candidates in engineering and computer science, with under 40 awards between them.

The programme will greatly increase the options open to postdocs in Spain - only 200 new contracts are available to them this year under other schemes. But the programme has been dogged by allegations that it has failed to break free of the favouritism that prevails in Spanish research institutions.

All researchers were required to obtain a letter of acceptance from the research centre

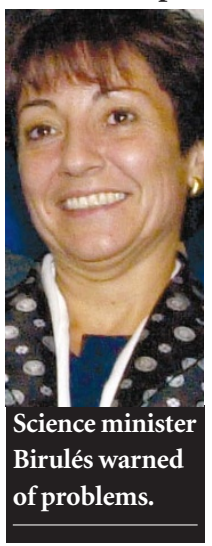
they wished to go to before applying to the Cajal programme, and science minister Anna Birulés warned in June that some institutions were damaging the programme by giving such letters only to local candidates. Spanish Congress members have proposed that some of the remaining 1,200 Cajal posts should be granted without an acceptance letter. www.mcyt.es/cajal nant of groundwater in Bangladesh or regions with similar flood-plain geology: "There was no indication in the hydrochemical or hydrogeological literature by 1992 that arsenic might be associated with [river and delta plains]."

The arsenic crisis in Bangladesh was caused by the sinking of over one million wells by foreign aid agencies and the Bangladeshi government from the 1970s. The effort - intended to reduce the incidence of water-borne disease in the region has instead put millions of Bangladeshis at risk of poisoning. "Bangladesh makes the Chernobyl disaster look like a Sunday-school picnic," says Richard Wilson, a Harvard University expert on arsenic poisoning.

The problem was not noticed until victims began showing external symptoms of arsenic poisoning: calluses on the palms and soles of feet, leading to skin cancers.

Most of the wells were sunk by UNICEF, the United Nations Children's Fund, in the 1970s and 1980s. The Bangladeshi government considered suing UNICEF, according to lawyers at Leigh, Day, but did not do so because there is a consensus that the arsenic problem couldn't have been anticipated then.

However, Bozena Michalowska of Leigh, Day claims that the BGS should have known about the potential for arsenic contamination in 1992.

Expert opinion on that point is divided. "Most hydrogeologists worth their salt would have known about it," claims John McArthur, a sedimentologist at University College London, who points out that reports of chronic arsenic poisoning started to emerge from neighbouring, and geologically similar, West Bengal in the mid-1980s. Dipankar Chakraborti, an epidemiologist at Jadavpur University in Calcutta, India, who identified the West Bengal cases, feels that the BGS should have been aware of his research. "They neglected the whole thing," he says.

But other experts point out that Chakraborti's work was not published in the international scientific literature, and only came to widespread attention in 1995. Paul Younger, a hydrogeologist at the University of Newcastle upon Tyne who has extensive experience of working in developing countries, says that "no one would have dreamt" of finding arsenic in river plains.

The fear of liability among foreign hydrogeologists, adds Younger, "could be a hell of a disincentive to performing low-cost schemes in developing countries that have been shown to be extremely effective".

Even Chakraborti fears that the case may deter others from working in Bangladesh and West Bengal. "If these agencies withdrew their support it would be a great loss," he says. wwww.bgs.ac.uk 